\title{
Mycobacterial Infections in Wild Boars (Sus scrofa) from Southern Switzerland: Diagnostic Improvements, Epidemiological Situation and Zoonotic Potential
}

\author{
Giovanni Ghielmetti ${ }^{1}$, Monika Hilbe ${ }^{2}$, Ute Friedel ${ }^{3}$, Chiara Menegatti ${ }^{4}$, Luca Bacciarini ${ }^{4}$, \\ Roger Stephan ${ }^{5}$, and Guido Bloemberg ${ }^{6}$ \\ ${ }^{1}$ University of Zurich \\ ${ }^{2}$ Vetsuisse Faculty University of Zurich \\ ${ }^{3}$ Affiliation not available \\ ${ }^{4}$ Cantonal Veterinary Office \\ ${ }^{5}$ Institute for Food Safety and Hygiene \\ ${ }^{6}$ National Reference Center for Enteropathogenic Bacteria and Listeria
}

April 28, 2020

\begin{abstract}
The occurrence of mycobacterial infections in different hosts and their implication as obligate or opportunistic pathogens remain mainly unclear. In addition to the well-known pathogenic members of the Mycobacterium tuberculosis - complex (MTBC), over 180 nontuberculous mycobacteria (NTM) species have been described. Although the large majority of the NTM are assumed to be non-pathogenic to most individuals, an increasing trend in NTM infections has been observed over the last decades. The reasons of such augmentation are probably more than one: improved laboratory diagnostics, an increasing number of immunocompromised patients and individuals with lung damage are some of the possible aspects. Mandibular lymph nodes of 176 hunted wild boars from the pre-Alpine region of Canton Ticino, Switzerland, were collected. Following gross inspection, each lymph node was subjected to culture and to an IS6110 based real-time PCR specific for MTBC members. Histology was performed of a selection of lymph nodes presenting gross visible lesions. Moreover, accuracy of matrix-assisted laser desorption ionization-time of flight (MALDI-TOF) mass spectrometry species identification was compared with sequence analysis of a combination of housekeeping genes. Mycobacteria of the MTBC were detected in five out of 176 wild boars (2.8\%; CI95\% $1.2-6.5)$ and were all confirmed to be Mycobacterium microti by molecular methods. In addition, based on the examined lymph nodes, NTM were detected in $57.4 \%$ (CI95\% $50.0-64.5$ ) of the wild boars originating from the study area. The 111 isolates belonged to 24 known species and three potentially undescribed Mycobacterium species. M. avium subsp. hominissuis thereby predominated $(22.5 \%)$ and was found in lymph nodes with and without macroscopic changes. Overall, the present findings show that, with the exception of undescribed Mycobacterium species where identification was not possible (3.6\%; 4/111), MALDI-TOF had a high concordance rate $(90.1 \% ; 100 / 111$ isolates) to the sequence based reference method.
\end{abstract}

\section{Introduction}

Bovine tuberculosis (bTB) is a chronic disease caused by members of theMycobacterium tuberculosis complex (MTBC) (Rodriguez-Campos et al., 2014). MTBC have been isolated from numerous different domestic and wild animal species. Recent epidemiological investigations have shown the fundamental role played by wildlife in the maintenance of the causal agents of bTB. This results in continuous interspecies transmissions 
from wild animals to livestock and vice versa, hindering national and international eradication programs (Atkins and Robinson, 2013, Garcia-Jimenez et al., 2016, Maria et al., 2015, Nigsch et al., 2018). Badger (Meles meles), free-ranging red deer (Cervus elaphus elaphus) and wild boar (Sus scrofa) are the most relevant known wild animals acting as a reservoir of bTB in Europe, including Great Britain. The ongoing geographic expansion of wild boar populations have raised concerns regarding the monitoring of several infectious diseases, including zoonotic plagues like bTB and hepatitis E (Gortazar et al., 2008, Martinelli et al., 2015). Beside the members of the MTBC and Mycobacterium leprae, the agent that causes Hansen's disease, over 180 species of nontuberculous mycobacteria (NTM) have been described (Gupta et al., 2018). NTM are commonly encountered in the environment and they have been isolated from a variety of sources, including water, feed, soil, dust, aerosol, invertebrates, protozoa or animals (Falkinham, 2015, Ghielmetti et al., 2018). Of these, two species are recognized as true pathogens for humans, namely M. marinum and M. ulcerans (Johansen et al., 2020). Nevertheless, more than 60 species of NTM are known to be opportunistic pathogenic to humans and other mammals, and infections with these emerging pathogens are now more common than tuberculosis in industrialized countries (Biet and Boschiroli, 2014, Griffith et al., 2007, Tortoli, 2014). Immunocompromised individuals are highly susceptible to opportunistic NTM infections and improved laboratory diagnostics have enabled more accurate detection of fastidious or extremely slow growing species. Despite the increasing relevance in mycobacterial infections, only restricted information on the occurrence and their diversity in wildlife is available. Moreover, although wild boars are among the most widely distributed large mammals in the world (Oliver et al., 1993), the literature concerning this species is mainly focused on (i) the presence of MTBC and (ii) the impact of NTM infections on the prevalence of MTBC (Boniotti et al., 2014, Chiari et al., 2016, Di Marco et al., 2012, Michelet et al., 2015, Naranjo et al., 2008, Richomme et al., 2010, Santos et al., 2009, Vicente et al., 2006). Canton Ticino is the most southern Canton of Switzerland and a large proportion of his border is shared with Italy. The territory encompasses an area of $2^{‘} 812$ square kilometre where the majority of the urban area is concentrated in the flat land and forests cover about one third of the alpine region. The wild boar presence in the territory has been documented during the XVI century. Thereafter, it disappeared and it is only since 1981 that it has been officially sighted again (Dipartimento Territorio / Finanze e Economia, 2010). The wild boars are distributed almost exclusively along flat- and hilly land, with the highest animal density observed in the southern districts of Mendrisio, Lugano and the lower part of the Maggia valley (Dipartimento Territorio / Finanze e Economia, 2010). The population increase is estimated at $100 \%-180 \%$, consequently the population can theoretically double or even triplicate in 12 months without control measurements. In order to regulate this growth, licensed hunters are allowed to hunt the animals each year in September without sex or hunting bag restrictions. Wild boar is one of the most hunted mammalians in the Canton of Ticino, second only to red deer.

Recent studies from Spain, Czech Republic, Brazil and Slovenia comprehensively evaluated the spectrum of NTM species in black pigs using molecular methods (Garcia-Jimenez et al., 2015, Gortazar et al., 2011, Pate et al., 2016, Trcka et al., 2006). It is significant to note that, the latter mentioned publications, describe significant differences in the spectrum of species isolated. Such differences may not be exclusively the result of geographic distribution of NTM, but the advance in molecular techniques and the progress in mycobacterial characterization led to enormous diagnostic improvements over the past decades (Tortoli, 2014). It is noteworthy, that the dissection of the M. avium complex (MAC) in the mentioned publications was performed at different levels, impeding a direct comparison of the isolated mycobacteria. The characterization of NTM from clinical samples is often a challenge for laboratory personal in routine diagnostic. Because of its rapidness, cost-effectiveness and high throughput the matrix-assisted laser desorption ionization-time of flight mass spectrometry (MALDI-TOF MS) technology has nowadays been integrated in the workflow of numerous diagnostic laboratories (Alcaide et al., 2018, Mediavilla-Gradolph et al., 2015, Murugaiyan et al., 2018). However, the accuracy achievable at present with genetic approaches remains superior to the MALDI-TOF-based species identification (Tortoli, 2014). Therefore, the accuracy and limitations of this method based on ordinary samples from veterinary origin should be evaluated. The present research used a panel of NTM showing a wide range of species isolated from a common source and verified the consensus grade between sequence analysis and MALDI-TOF. This study aimed (i) to determine the occurrence and 
diversity of mycobacterial species among healthy wild boar hunted in Canton Ticino, (ii) to identify the geographical distribution of mycobacterial species, and (iii) to compare two different diagnostic identification approaches for the genus Mycobacterium .

\section{Materials and Methods}

\section{Collection of Samples}

Hunting seasons in Switzerland are regulated by the Cantonal Veterinary Offices independently. In total, 1436 and 1588 wild boars were hunted in Canton Ticino in 2017 and 2018, respectively. Mandibular lymph node of 86 and 90 animals were collected during the two hunting periods of the study and the weight of every sampled wild boar was determined. Assuming an estimated population size of 2500-3000 animals, approximatively $5 \%$ of the population was analyzed over a two-year period.

Sex, age and the exact geographical position of each animal were recorded directly on the field. Age classification was based on tooth eruption patterns: animals $<6$ months of age were recorded as juveniles, those between six months and two years of age as yearlings, and adult animals older than two years composed the last group. Trained personnel of the Cantonal Veterinary Office excised lymph nodes by using sterile dissection knives and scalpels. Each sample was immediately packed into sterile containers and transported to the laboratory under cooled conditions.

\section{Microbiological Procedures}

Sample preparation and mycobacterial cultures were performed as described elsewhere (Ghielmetti et al., 2018). Briefly, BBL MGIT liquid media tubes supplemented with Bactec MGIT 960 growth supplement, BBL MGIT PANTA (Polymyxin B, Amphotericin B, Nalidixic acid, Trimethoprim, Azlocillin) antibiotic mixture (Becton, Dickinson, BD, Allschwil, Switzerland) and $50 \mu \mathrm{g} / \mathrm{ml}$ sodium-pyruvate were each inoculated with 0.5 $\mathrm{ml}$ of decontaminated and homogenized specimen. In addition, one Löwenstein-Jensen and one Stonebrink agar slants (BD) were inoculated with the same inoculum and incubated up to eight weeks at $37^{\circ} \mathrm{C}$. In order to obtain pure mycobacterial cultures, subcultures on 7H10 agar-plates and on Stonebrink agar slants (BD) were performed at intervals of three to ten days. Simultaneously, $400 \mu$ l of culture inoculum was suspended in $100 \mu \mathrm{l}$ ATL buffer (Qiagen, Hilden, Germany) and transferred onto a Lysing Matrix E tubes (MP Biomedicals, Eschwege, Germany). Genomic DNA was extracted through mechanical cell lysis using a TissueLyser II (Qiagen, Hilden, Germany) and enzymatic digestion with Proteinase K (Qiagen) overnight. Automated DNA purification was performed using the QIAcube instrument in accordance with the QIAamp cador Pathogen Mini Kit protocol (Qiagen). DNA concentration in the final eluate was measured by reading the absorbance at $260 \mathrm{~nm}$ using a NanoDrop 2000c Spectrophotometer (Thermo Fisher Scientific, Reinach, Switzerland), diluted to a maximal concentration of $100 \mathrm{ng} / \mu \mathrm{l}$ and stored at $-20^{\circ} \mathrm{C}$ until use. Purified DNA was used for direct MTBC detection using the qPCR assay targeting insertion sequence IS6110 as described by Reed et al. with slight modifications (Reed et al., 2016). Briefly, the MTB IS6110 probe was doublequenched with iQ500 and BHQ1 instead of ZEN and 3IABkFQ, respectively. Moreover, the qPCR assay internal control was substituted by eGFP as described by Hoffmann and colleagues and performed on a 7500 Fast real-time PCR system (Applied Biosystems, Zug, Switzerland) (Hoffmann et al., 2006).

DNA from cultured mycobacteria was extracted by inoculating a loop-full of cell materials into $200 \mu$ of chelating ion-exchange resin (InstaGene Matrix, Cressier, Switzerland) and centrifuged at $13000 \mathrm{~g}$ for 10 minutes. The supernatant was used in downstream reactions.

Pure cultures that presented acid-fast bacilli (AFBs) by Ziehl-Neelsen (ZN) staining and negative MTBC qPCR results were classified as NTM and further characterized by sequence analysis of a combination of housekeeping genes and matrix-assisted laser desorption/ionization time-of-flight mass spectrometry (MALDITOF MS). Sanger sequencing of 16S rRNA (Scherrer et al., 2018), rpoB (Adékambi et al., 2003) andhsp65 (Telenti et al., 1993) housekeeping genes was performed in duplicates followed by gene homology analy- 
ses. For isolates identified as members of the MAC, the completehsp65 gene was sequenced as proposed by Turenne et al.using primers MAChsp65F and MAChsp65R (Turenne et al., 2006). DNA sequencing was performed at Microsynth (Balgach, Switzerland). Resulting sequences were assembled using CLC Genomics Workbench 7.5.1 (Qiagen) and BLAST similarity searching for multiple sequence alignment was performed (https://blast.ncbi.nlm.nih.gov/Blast.cgi). Control strains included were $M$. avium subsp. avium ATCC 25291, M. aviumsubsp. hominissuis ATCC 700898, M. peregrinum ATCC 700686. For samples resulted positive by direct MTBC real-time PCR, mycobacteria could not be cultivated from any of the described culture media, even after 12 months of incubation. Molecular characterization by mycobacterial interspersed repetitive unit and variable number tandem repeats (MIRU-VNTR) and species determination using spoligotyping were therefore performed using DNA extracts of lymph nodes as previously described (Ghielmetti et al., 2017).

\section{MALDI-TOF Mass Spectrometry}

Inactivation and preparation of the isolates for MALDI-TOF MS analysis was performed using the Mycobacteria Extraction Method (MycoEX) in accordance with the manufacturer. In order to enable optical evaluation of the tested colonies and because the quality of the spectra obtained from isolates grown on solid media is better than those obtained from liquid media, 7H10 agar-plates were chosen as culture medium for MALDI-TOF MS analysis (Kodana et al., 2016, Lotz et al., 2010). A loopful of culture from solid medium was transferred into a $1.5 \mathrm{ml}$ Eppendorf tube with $300 \mu \mathrm{L}$ of HPLC-water and inactivated for $30 \mathrm{~min}$ at $99^{\circ} \mathrm{C}$ under biosafety level 3 conditions. After a centrifugation step of 2 min at $13000 \mathrm{~g}$, the supernatant was discharged the pellet was re-suspended in $300 \mu \mathrm{L}$ of HPLC-water and $900 \mu \mathrm{L}$ of ethanol. Thereafter, centrifugation was repeated and the supernatant was discharged. The tubes were left open enabling the pellets to dry at room temperature. A spatula-tip full of bead suspension (Zirconia/Silica; BioSpec, Bartlesville, USA) and $10-50 \mu \mathrm{L} \mu \mathrm{l}$ of acetonitrile were added to the pellets, depending on the volume of the pellets. Mycobacterial cells were disrupted by vortexing at maximal speed for $1 \mathrm{~min}$ and $25-50 \mu \mathrm{l}$ of $70 \%$ formic acid were added, depending on the volume of the pellets. In conclusion, the tubes were centrifuged at the same conditions as above and $1 \mu \mathrm{l}$ of the supernatant was spotted on the MALDI-TOF target plates (MSP 96 target ground steel; Bruker Daltonics, Billerica, MA, USA) in duplicates. At this point, the target plates were allowed to dry at room temperature and then taken to biosafety level 2 conditions. Thereafter $1 \mu l$ of matrix was added to each spot (HCCA, $\alpha$-cyano-4-hydroxycinnamic acid).

Peptide mass spectra were acquired in a linear positive ion mode at a maximum laser frequency of $60 \mathrm{~Hz}$ across a mass to charge ratio (m/z) of 2,000 to 20,000 Da using the Microflex LT benchtop operating system (Bruker Daltonik GmbH, Fällanden, Switzerland). Each spot was measured twice using the MBT_FC.par FlexControl method and analysed by the FlexAnalysis 3.3 software (Bruker Daltonik GmbH). The highest $\log$ score value was compared with the MBT Mycobacteria Library 4.0, containing 880 main spectrum profiles (MSP), representing 159 mycobacterial species. AnEscherichia coli reference strain provided by the manufacturer was used in each run as a calibrator and for quality control. Log scores values (LSV) between 2.0 and 3.0 were considered as acceptable, between 1.8 and 2.0 were treated with caution and considered consistent when the same species was the only one suggested by the software with a LSV above 1.8. Lower LSV $(<1.8)$ were interpreted as incorrect and recorded as "no identification possible" (Saleeb et al., 2011). For each species isolated, the measured spectra of one isolate were exported in specific main spectrum profiles (MSP) using the MALDI Biotyper Compass Explorer 4.1 software. Each MSP was matched against the MBT Mycobacteria Library 4.0.

\section{Macroscopic and Histological Examination}

After removal of fat and connective tissue, qualified staff inspected the lymph nodes macroscopically and recorded pathological changes. A subset of samples was additionally submitted for histology. Selection criteria were focusing on infections with the seven most prevalent Mycobacterium species and presenting macroscopic lesions. In addition, all lymph nodes that tested positive for MTBC by real-time PCR were submitted for histological examination. Samples were fixed in $10 \%$ buffered formalin and embedded in paraffin. Two to three-micron-thick tissue sections were obtained and stained with hematoxylin and eosin (HE). Additionally, 
in cases where lesions consistent with mycobacterial infections were observed after HE staining, an additional ZN staining was performed.

Geographical Distribution and Statistical Analysis. The geographical distribution of the lymph nodes showing growth of mycobacteria and the circulation of the different NTM on the territory were investigated using the free software QGIS Desktop 3.6.1. Based on the collected data regarding sex and age of the animals, statistical analysis was performed using GraphPad Prism 8.2.1 (GraphPad Software, San Diego, USA). Fisher's exact test was used to evaluate different age groups and the presence of viable NTM isolated from their lymph nodes. Moreover a possible association between the isolation of Mah, the most prevalent isolated species, and the three age groups was investigated with the same test. Statistical significance was set to $P$-value $<0.05$.

\section{Ethics Statement}

All animals samples used in this study originated from legally hunted wild boars in accordance with Swiss legislation (Hunting Law SR 922 and Animal Welfare Act SR 455). An ethical approval or permit for animal experimentation was not applicable.

\section{Results}

Of the 176 investigated wild boars collected during 2017 and 2018, mandibular lymph nodes from 101 (57.4\%; $\mathrm{CI}_{95 \%} 50.0$ - 64.5) animals showed typical growth of Mycobacterium spp. (111 isolates in total) and AFBs by ZN staining were observed. The sequenced genes (16S rRNA, rpoB, hsp65) assigned 108 of 111 isolates to 24 described Mycobacterium species (Table 1). Three single isolates could not be classified to any known mycobacterial species and may represent new species. M. avium subsp. hominissuis (Mah) predominated with $22.5 \%$ of the isolates, followed by . nonchromogenicum with $21.6 \%$ of the isolates.

Five samples derived from three juvenile and two adult wild boars were positive by MTBC real-time PCR. Since no growth of mycobacteria over a 12 months incubation period could be achieved, species identification by direct spoligotyping using extracted DNA from the lymph nodes was performed. All five samples presented the same spoligotype signature SB0118 characterized by the presence of spacers 37-38 (www.Mbovis.org). The same signature is also known in the international spoligotyping database SpolDB4 as ST 539 and is indicative for M. microti(Brudey et al., 2006). Mycobacterial co-infections were detected in nine samples $(5.1 \%)$, originating from adults $(\mathrm{n}=7)$ and juveniles $(\mathrm{n}=2)$ and comprising one M. microtipositive lymph node. Seven animals presented co-infections with two NTM (M. avium / M. vaccae, twice $M$. avium / M. nonchromogenicum , M. phlei / M. nonchromogenicum, M. nonchromogenicum / M. chimaera intracelullare group, M. scrofulaceum /M. florentinum, M. vaccae /Mycobacterium sp.) one animal presented co-infection with three NTM (M. fortuitum complex/M. engbaekii/M. vaccae ) and one animal M. microti/M. neoaurum - Molecular characterization based on 24 MIRU-VNTR loci was performed on four out of five M. microti containing samples and showed an identical code, suggesting a common source of infection or a transmission chain (Supplementary material S1). The geographical localization of the wild boars infected with $M$. microti is displayed in Figure 1A.

Adult wild boars were more prone to be infected with mycobacteria in comparison to juvenile animals or yearlings (Fig. 2). Overall, $74.4 \%$ of the analysed lymph nodes originating from adult animals showed growth of mycobacteria. Only $54.9 \%$ and $45.8 \%$ of the juveniles and yearlings presented viable NTM respectively $(P$-value $<0.05)$. A correlation between infected animals and their sex was not found, nor a significant association between the isolation of $M a h$ and the three age groups (juveniles versus yearlings $P=0.151$; juveniles versus adults $P=0.804$; yearlings versus adults $P=0.384$ ).

The distribution of the different NTM circulating among the analyzed animals was investigated based on the geographical data collected. The hunted wild pig population was divided into seven districts of the study 
area and, with the exception of the three northern districts where a low number of samples were obtained; a homogeneous distribution of the NTM cultured is shown in the remaining four districts (Fig 1B).

\section{Macroscopic and Histological Examination}

Of the lymph nodes from the 101 wild boars showing growth of Mycobacterium spp., $25.7 \%$ showed macroscopic pathological lesions (Table 2). Macroscopic visible lesions such as single or multiple caseous, necrotic and calcified nodules of different sizes $(1-30 \mathrm{~mm})$ were observed $(\mathrm{n}=14)$. In addition to the described nodular lesions, lymph node enlargement, discoloration and induration were recorded $(\mathrm{n}=26)$. Histologically, in $70 \%$ of the samples presenting nodular lesions, a moderate granulomatous lymphadenitis with scarce giant cells of Langhans type surrounding or adjacent of a mild to moderate focal-extensive necrosis was visible. The lymph nodes showed additionally a moderate to severe reactive hyperplasia and a mild to moderate eosinophilic lymphadenitis. Mah, the predominant species identified in the present study, was found in lymph nodes with and without macroscopic changes. On the contrary, M. microti $(\mathrm{n}=5)$ and M. florentinum $(\mathrm{n}=3)$ infections were always associated with visible lesions such as caseous, necrotic and calcified nodules. A subset of lymph nodes $(\mathrm{n}=14)$ presenting macroscopic lesions compatible with mycobacterial infections were examined histologically. Lymph nodes of animals infected by M. microti and M. florentinumshowed all granulomatous lymphadenitis characterized by focal-extensive necrosis and mild inflammatory infiltration of epithelioid macrophages, neutrophils, multinucleated Langhans giant cells and eosinophils (Fig. 3A and $3 \mathrm{C})$. In three cases dystrophic calcifications were markedly present. Overall, the lesions observed macroscopically and histologically were circumscribed and of mild to moderate entity. Ziehl-Neelsen staining revealed scanty AFBs according to the IUATLD and WHO grading scales. Samples that presented visible lesions compatible with tuberculosis and tested positive for M. microti showed "croissant-like" or S-shaped AFBs, which is commonly associated with this species (van Soolingen et al., 1998). Acid-fast bacilli were observed extracellular and within macrophages (Fig. 3B).

\section{MALDI-TOF Mass Spectrometry}

By setting a LSV cut-off at [?] 2.0, MALDI-TOF MS was able to correctly identify 80 isolates out of 111 $(72.1 \%)$ appertaining to 19 species using sequence analysis (16s rRNA gene, rpoB and $h s p 65$ ). By lowering the cut-off for species identification at [?] 1.8 as previously proposed for mycobacterial species (Alcaide et al., 2018, Pranada, 2015), 100 isolates (90.1\%) from the same 19 species were correctly assigned (Table 1). Two isolates, one $M$. vulneris misidentified as M. colombiense(LSV 2.08) and a second one, presumably representing a new species and misidentified as M. arupense (LSV 1.81) led to discrepant results (Supplementary material S2-S4). The remaining 9 isolates, classified as "no identification possible" by MALDI-TOF MS, were identified by sequence analysis as $M$. colombiense ( $3 / 3$ isolates) $M$. scrofulaceum ( $2 / 2$ isolates), $M$. monacense and $M$. terraecomplex (one isolate each), and two additional undescribed Mycobacterium spp..

\section{Discussion}

In five out of 176 analyzed wild boars $\left(2.8 \%\right.$ CI $_{95 \%} 1.2$ - 6.5) DNA appertaining to a member of the MTBC was detected by RT-PCR. The observed prevalence is in accordance with a previous study in wild boar originating from three different Swiss cantons, where the observed prevalence was 3.6\% (Schoning et al., 2013). The present five samples were further analyzed by spoligotyping and molecular characterization based on 24 loci, revealing a common source of infection or a transmission chain of M. microti (Supplementary material). Based on these findings and the available information from literature, a transboundary presence in the Swiss and the Italian border region along the Province of Como is shown (Boniotti et al., 2014). The identical spoligotyping and MIRU-VNTR profile (ETRs loci) was observed by Boniotti and colleagues in five out of 26 isolates analyzed between 2007 and 2009. Over this period, a slightly higher prevalence of $5.8 \%$ was described in Italy. This suggests a persistent presence of one M. microti strain affecting the local wild boar population over at least a decade. The spoligotyping profile SB0118, shared by all isolates, is the only profile detected in Switzerland so far, independently from the host species and showing 
a large host range. Additionally to wild boars, this spologotype has been isolated from domestic cats, South American camelids and captive gibbons in Switzerland (unpublished results). Interestingly, different wild rodent species originating from hot spots areas examined for MTBC were all tested negative by molecular and cultural methods (manuscript in preparation). The predominant species identified in this study belonged to the MAC (Table 1). This complex comprises several clinically important mycobacterial species (van Ingen et al., 2018). M. avium ( $n=25)$ was the most prevalent member of the complex, followed by $M$. colombiense (n=3), M. chimaera/intracelullare group $(n=2)$ and $M$. vulneris $(n=1)$ (Table 1). M. avium is a thermophilic slowly growing mycobacterium and comprises four subspecies, namely $M$. avium subsp. avium (Maa), M. aviumsubsp. silvaticum (Mas), M. avium subsp.hominissuis (Mah) and M. avium subsp.paratuberculosis (Map). Sequencing of the 3' region of thehsp65 gene can unambiguously distinguish between these subspecies (Turenne et al., 2006). Mah has the broadest host range compared to the other members of the MAC, nevertheless, a clear differentiation between environmental and host-specific members of the MAC is necessary to better understand its distribution, host-adaptation and clinical implications (Turenne et al., 2006). Contrary to the observations from a Spanish study (Garcia-Jimenez et al., 2015), where MAC was isolated more often from subadults, no correlation between MAC and age of the animals was observed in the present survey. Overall, a significant increase of mycobacterial infection correlated with an increase of age (Figure 2), suggesting that the isolated mycobacteria are probably the results of a prolonged infection or colonization more than a transient presence. This is corroborated by the observation that coinfections, including one animal infected by $M$. microti, were mostly in adult animals and none of the wild boars from the juvenile group was infected by multiple species. Co-infections with MTBC/NTM or two different NTM have been described in animals and humans (Garcia-Jimenez et al., 2015, Gcebe and Hlokwe, 2017, Lim et al., 2011, Stepanyan et al., 2019, Yilmaz et al., 2017). In such cases, it is mostly unclear which agent infected first, and the host protective effect of the first infection from a second one remains unknown. A possible explanation for this increased number of co-infection in older individuals may be a cumulative effect with time and exposure. Overall no effect from NTM isolation and MTBC infection could be observed due to the small number of MTBC positive animals and one animal being co-infected with $M$. microti and $M$. neoaurum . In the past decades, various research articles attempted to describe MAC reservoirs and infection sources for humans and animals through molecular analyses. These included environmental surveillances, e.g. drinking water, bathrooms and hot tubs (Eisenberg et al., 2012, Falkinham et al., 2008, Hilborn et al., 2008). Noteworthy, certain studies reported a close genetic relatedness between human and swine isolates (Johansen et al., 2007, Mobius et al., 2006). In most cases, however, the source of infection remained unclear. The discrimination of Map with the MALDI-TOF technique has been assessed in previous studies (Ravva et al., 2017, Ricchi et al., 2017). The $25 \mathrm{MAC}$ isolates tested in the present study were all confirmed to be Mah by sequence analysis, and the first subspecies suggestion provided by MALDI-TOF was generally correct (80\%). However, differentiation at MAC subspecies level with MALDI-TOF has to be performed with carefulness and might require additional gene sequence analysis. Wild boars (Sus scrofa) are among the most widely distributed large mammals worldwide. Their natural range extends from Western Europe and the Mediterranean basin to Eastern Russia, Japan and South-east Asia (Massei et al., 2015). The high mobility associated with the highest reproductive capacity among ungulates, enable an annual population growth rate of $250 \%$ under favorable food and weather conditions (Ebert et al., 2012, Gethoffer et al., 2007). Supplemental feeding of wild ungulates is prohibited by law in several Swiss Cantons, including Ticino. Despite this order and the annual population reduction by hunters, the population in the study area is rising, augmenting the animal-to-animal as well as the animal-to-human contact probabilities. Since the hunted animals of the present study were judged to be in an overall healthy condition suitable for human consumption, the Mah infection rate of $14 \%$ observed in the mandibular lymph node is noteworthy and may represent a veterinary public health concern. Only few publications extensively investigated the presence of NTM in wild boar (Garcia-Jimenez et al., 2015, Gortazar et al., 2011, Pate et al., 2016, Trcka et al., 2006). M. chelonaewas the most frequent NTM species isolated by Garcia-Jimenez et al ., whilst Gortazar and colleagues did not detect $M$. chelonaein 124 wild boars tested. In the present study M. chelonae was not detected, suggesting a diversity of NTM species at geographical level. Members of the MAC were also irregularly detected: $M$. intracellulare, Maa, Mah and M. colombiense are nowadays classified as MAC 
members implicated as relevant pathogens in human and veterinary medicine. The dissection of the MAC at species or subspecies level is not always trivial (Turenne et al., 2006). It is therefore fundamental to implement advanced approaches in order to identify the exact species involved and estimate their relevance as potential infection source for consumers. Previous reports described NTM isolation rates in wild pigs varying from 8.9\% (Trcka et al., 2006), 16.1\% (Gortazar et al., 2011), 16.8\% (Garcia-Jimenez et al., 2015) to 18.2\% (Pate et al., 2016). In addition to the above mentioned NTM, M. peregrinum, M. nebraskense, M. lentiflavum, $M$. nonchromogenicum, M. engbaeki and M. septicumwere isolated from wild boar in recent studies from Brazil (Lara et al., 2011), Czech Republic (Trcka et al., 2006), Italy (Boniotti et al., 2014), Slovenia (Pate et al., 2016) and Spain (Garcia-Jimenez et al., 2015, Gortazar et al., 2011). Among the remaining species isolated in the present study for the first time, $M$. florentinum is noteworthy regarding the granulomatous lesions observed in the three affected animals. Wild boars are generally organized in social packs grouped around a nucleus of two or three sexually mature breeding sows. The rest of the group consists of newborn piglets and juvenile individuals $(<20$ months of age) from the previous litter. Males are expelled from the pack by the time they reach sexual maturity. The average pack size can vary between 5 and 10 animals (Briedermann, 2009). The territory covered by packs may vary widely between geographical areas, strongly dependent from the landscape, presence of water and human influence. Packs covered 8-30 km2 in the Jura-region of Switzerland (Baettig, 1993), 2-40 km² in southern France (Spitz, 1992) and 1-4 km² in Italy (Boitani et al., 1994). A single group of animals tends to defends its core area: $1-3 \mathrm{~km}^{2}$ (Spitz, 1992), $<1 \mathrm{~km}^{2}$ (Boitani et al., 1994) while the rest of the territory may overlap with home ranges of neighboring packs (Leuenberger, 2004). In contrast to packs, which tend to use only a small portion of their territory and move to another range at regular intervals, the adult male has a single territory that can range up to $50 \mathrm{~km}^{2}$. These individuals are able to move across the entire territory at daily basis, playing a crucial role in the spread of animal and zoonotic pathogens (Nugent et al., 2015, Schulz et al., 2019, Spitz, 1992). This high mobility may also be one of the possible explanations for the homogenous spread of the NTM species isolated across Canton of Ticino. Because of their rooting behavior and eating habits, wild boars are often in contact with environmental NTM species. Moreover the occasional consumption of dead small rodents and other carrion can enable direct transmission of pathogenic mycobacteria. However, this does not seem to cause generalization and clinical disease in all individuals, presumably because of the previously suggested genetic resistance of wild boars against bTB causing agents and possibly other mycobacterial species (Acevedo-Whitehouse et al., 2005, Dondo et al., 2007). An interesting finding was the presence of granulomatous lesions compatible with tuberculosis observed in a subset of lymph nodes analyzed. In particular, samples in which M. microti and $M$. florentinumwere detected, showed granulomatous lymphadenitis characterized by focal-extensive necrosis and in some cases dystrophic calcifications. These calcifications and the paucibacillary nature of the lesions suggests, however, a circumscribed and chronic process. Because of the design of the present study, it was not possible to assess the presence of further lesions in the wild boar carcass. Mandibular lymph nodes have been described to be the preferred entry point for mycobacteria in wild boars (Queiros et al., 2019). This is probably due to its eating habits allowing the intake of environmental contaminations and infected feed sources. After oro-nasal infection, viable microorganisms often concentrate in mandibular lymph nodes and from there are eliminated, persist or eventually disseminate throughout other organ systems. The mentioned lymph nodes are the most likely organ for visible lesion caused by MTBC in adult animals and in a relevant proportion of cases this is the only organ affected (Dondo et al., 2007, Martin-Hernando et al., 2007). The occurrence of visible lesions caused by $M$. microti in wild boars has been described previously (Boniotti et al., 2014). M. microti, although believed to be less pathogenic, has been described to cause extensive lesions, indistinguishable from those caused by other MTBC members in immunocompetent individuals (Frank et al., 2009, Geiss et al., 2005, Niemann et al., 2000, van Soolingen et al., 1998, Emmanuel et al., 2007). To the authors' knowledge, this is the first time that similar lesions caused by $M$. florentinum are described in veterinary medicine. Classified as a slow growing Mycobacterium, M. florentinum is an opportunistic human pathogen isolated from immunocompetent and immunocompromised patients with various pulmonary disorders and lymphadenitis (Tortoli et al., 2005). Macroscopically and histologically the lesions caused by the two above mentioned species were indistinguishable. These findings highlight the importance of molecular characterization methods that allows a rapid and reliable differentiation of MTBC members from 
other NTM. The geographical distribution of M. florentinum appears to be widespread since human cases have been described in Italy, Finland, Japan and the US (Nukui et al., 2014, Syed et al., 2010, Tortoli et al., 2005). Interestingly, a significant proportion of Mycobacterium spp. other than M. microti and $M$. florentinum, were isolated from tissue samples that did not present granulomatous lesions or pathological finding in general (Table 2). Similar findings were recently described by two studies focused on lymph nodes from slaughter pigs (Mann et al., 2014, Muwonge et al., 2012). The presence of viable mycobacteria without evidence of histopathological granulomatous lesions might represent an early stage of the infection, which is not yet morphologically identifiable and in most cases probably results in the elimination of the microorganism (Mann et al., 2014). On the other hand, a certain contamination degree with environmental mycobacteria is not to be excluded. Because of the small size of the samples, disinfection of the mandibular lymph nodes superficial area was not possible. Based on the high sensitivity of the MTBC specific RT-PCR adopted, cross-contamination of the samples can be excluded. M. microti DNA was identified exclusively in lymph nodes presenting visible lesions and from animals processed on different days. Even though an infection was not proven with histology in all lymph nodes showing growth of Mycobacterium sp., the technique and instruments used for samples collection were above the ordinary hygiene standards adopted for meat processing. This indicates that an alarming high number of viable mycobacteria from different species are present in raw meat from hunted wild boars. Overall, MALDI-TOF MS showed to be reliable for the identification of NTM derived from veterinary specimens. Although the threshold recommended by the manufacturer enable the correct identification of only $72.1 \%$, different authors evaluated lower cut-off values for mycobacteria with satisfactory results (Alcolea-Medina et al., 2019, Buchan et al., 2014, MediavillaGradolph et al., 2015, Saleeb et al., 2011). In the authors' opinion, an important drawback of the MALDITOF MS technology in comparison with sequence analysis of housekeeping genes like e.g. 16S rRNA, is that yet undescribed species will go undetected, either without any identification or as misidentification. In this study, three NTM species: M. colombiense (3/3 isolates) M. scrofulaceum( $2 / 2$ isolates) and $M$. monacense (one isolate) could not be identified although present in the MBT Mycobacteria Library 4.0. The most probable explanation for this is the restricted number of MSP (main spectrum profiles) present in the library used as reference. Moreover, one isolate of M. vulneris was misidentified as M. colombiense with a LSV of 2.08, demonstrating that closely related species still represent a challenge to be unambiguously identified and require sequence analysis for accurate assignment. An interesting aspect noticed during the present study, was the erroneous classification by BLAST analysis of the $r p o B$ gene sequences derived from three $M$. diernhoferi isolates tested. According to NCBI BLAST the closest species was $M$. aurum with a percentage identity score of $97 \%$. The MALDI-TOF MS analysis suggested $M$. diernhoferi with an unequivocal LSV [?] 2.0 for all three strains. Hence, a NCBI nucleotide search for $M$. diernhoferi rpoB sequences allowed the finding of an identical sequence, namely whole genome shotgun sequence derived from strain IP141170001 BioProject PRJNA354248. In our experience, this is a rare case, where a submitted sequence could not be found by similarity search, potentially leading to a misidentification of the analysed samples. Because NTM infections are not notifiable to public health authorities in most countries, data regarding the incidence and prevalence of diseases caused by these agents are lacking or difficult to compare between different countries. Switzerland is faced, as any other country, with NTM infections in humans (Kuznetcova et al., 2012, Latshang et al., 2011, Taillard et al., 2003), and identification of local potential infection sources is therefore of great relevance. Regarding the two species of NTM that have been most frequently isolated in the present study ( $M$. avium subsp.hominissuis and $M$. nonchromogenicum ), MAC members have been described as the most common cause of NTM diseases in human in Northern Europe (Hoefsloot et al., 2013), Japan (Nishiuchi et al., 2017), Korea(Ko et al., 2018) and North America (Boyle et al., 2015). The classical localization affected by MAC is the respiratory system and in most cases, the source and route of infection remains unknown.

In conclusion, a remarkable number of mandibular lymph nodes collected from wild boars presented viable mycobacteria. Although the zoonotic risk of the isolated NTM remains unclear, it must be emphasized that, the hunted animals were intended for human consumption and among the isolated species $(\mathrm{n}=24)$, the large majority $(n=18)$ has been described as human pathogens. In order to assess the possible role played by wild animals into the spread of mycobacteria, further epidemiological investigations including isolates from different sources are required. Moreover, the present findings show that, MALDI-TOF MS has 
a high concordance rate to the reference method and because of his rapidness, cost-effectiveness and high throughput, represent a valid diagnostic tool for identification of NTM species in veterinary medicine.

\section{Acknowledgments}

The authors would like to thank the local hunter and the game wardens from Canton Ticino, without their cooperation, this study would not have been possible. The authors gratefully acknowledge Ella Hubschke and Fenja Rademacher for skilled technical assistance.

\section{Conflict of Interest Statement}

The authors declare that they have no conflict of interest.

\section{Data available on request from the authors}

The data that support the findings of this study are available from the corresponding author upon reasonable request.

\section{References}

Acevedo-Whitehouse, K., J. Vicente, C. Gortazar, et al., 2005: Genetic resistance to bovine tuberculosis in the Iberian wild boar. Molecular ecology, 14, 3209-3217, doi:10.1111/j.1365-294X.2005.02656.x (2005).

Adekambi, T., P. Colson and M. Drancourt, 2003: rpoB-based identification of nonpigmented and latepigmenting rapidly growing mycobacteria. J. Clin. Microbiol., 41, 5699-5708 (2003).

Alcaide, F., J. Amlerova, G. Bou, et al., 2018: How to: identify non-tuberculous Mycobacterium species using MALDI-TOF mass spectrometry. Clinical microbiology and infection: the official publication of the European Society of Clinical Microbiology and Infectious Diseases, 24, 599-603, doi:10.1016/j.cmi.2017.11.012 (2018).

Alcolea-Medina, A., M. T. C. Fernandez, N. Montiel, et al., 2019: An improved simple method for the identification of Mycobacteria by MALDI-TOF MS (Matrix-Assisted Laser Desorption- Ionization Mass Spectrometry). Scientific reports, 9, 20216, doi:10.1038/s41598-019-56604-7 (2019).

Atkins, P. J. and P. A. Robinson, 2013: Bovine tuberculosis and badgers in Britain: relevance of the past.Epidemiology and infection, 141, 1437-1444, doi:10.1017/S095026881200297X (2013).

Baettig, M., 1993: Das Schwarzwild . Berichte der St.Gallischen Naturwissenschaftlichen Gesellschaft.

Biet, F. and M. L. Boschiroli, 2014: Non-tuberculous mycobacterial infections of veterinary relevance.Res. Vet. Sci., 97 Suppl, S69-77, doi:10.1016/j.rvsc.2014.08.007 (2014).

Boitani, L., L. Mattei, D. Nonis and F. Corsi, 1994: Spatial and activity patterns of wild boars in Tuscany, Italy. J Mammal, 75, 600-612, doi:Doi 10.2307/1382507 (1994).

Boniotti, M. B., A. Gaffuri, D. Gelmetti, et al., 2014: Detection and molecular characterization of Mycobacterium microti isolates in wild boar from northern Italy.J Clin Microbiol, 52, 2834-2843, doi:10.1128/JCM.00440-14 (2014). 
Boyle, D. P., T. R. Zembower, S. Reddy and C. Qi, 2015: Comparison of clinical features, virulence, and relapse among Mycobacterium avium complex species. American journal of respiratory and critical care medicine, 191, 1310-1317, doi:10.1164/rccm.201501-0067OC (2015).

Briedermann, L., 2009:Schwarzwild . Franckh-Kosmos.

Brudey, K., J. R. Driscoll, L. Rigouts, et al., 2006: Mycobacterium tuberculosis complex genetic diversity: mining the fourth international spoligotyping database (SpolDB4) for classification, population genetics and epidemiology.BMC microbiology, 6, 23, doi:10.1186/1471-2180-6-23 (2006).

Buchan, B. W., K. M. Riebe, M. Timke, et al., 2014: Comparison of MALDI-TOF MS with HPLC and nucleic acid sequencing for the identification of Mycobacterium species in cultures using solid medium and broth. Am J Clin Pathol, 141, 25-34, doi:10.1309/AJCPBPUBUDEW2OAG (2014).

Chavarria, M., L. Lutwick and B. L. Dickinson, 2018: TB or not TB? Mycobacterium celatum mimicking Mycobacterium tuberculosis : A case of mistaken identity.IDCases, 11, 83-87, doi:10.1016/j.idcr.2018.01.015 (2018).

Chiari, M., N. Ferrari, D. Giardiello, et al., 2016: Spatiotemporal and ecological patterns of Mycobacterium microti infection in wild boar (Sus scrofa ). Transboundary and emerging diseases, 63, e381-388, doi:10.1111/tbed.12313 (2016).

Dholakia, Y. N., 2017:Mycobacterium Interjectum isolated from an immunocompetent host with lung infection. International journal of mycobacteriology,6, 401-403, doi:10.4103/ijmy.ijmy_112_17 (2017).

Di Marco, V., P. Mazzone, M. T. Capucchio, et al., 2012: Epidemiological significance of the domestic black pig (Sus scrofa) in maintenance of bovine tuberculosis in Sicily. J Clin Microbiol, 50, 1209-1218, doi:10.1128/JCM.06544-11 (2012).

Dipartimento Territorio / Finanze e Economia, 2010: Rapporto della commissione delle petizioni e dei ricorsi sulla petizione 3 giugno 2009 presentata dall'Unione contadini ticinesi (UCT) e dalla Federazione viticoltori della svizzera italiana (FEDERVITI) "Cervi e cinghiali: che disastro!".

Dondo, A., S. Zoppi, F. Rossi, et al., 2007: Mycobacteriosis in wild boar: results of 2000-2006 activity in North-Western Italy. Epidemiol. et sante anim., 51, 35-42 (2007).

Ebert, C., F. Knauer, B. Spielberger, et al., 2012: Estimating wild boar Sus scrofa population size using faecal DNA and capture-recapture modelling. Wildlife Biol, 18, 142-152, doi:10.2981/11-002 (2012).

Eisenberg, T., R. Volmer, U. Eskens, et al., 2012: Outbreak of reproductive disorders and mycobacteriosis in swine associated with a single strain of Mycobacterium aviumsubspecies hominissuis . Veterinary microbiology, 159, 69-76, doi:10.1016/j.vetmic.2012.03.013 (2012).

Emmanuel, F. X., A. L. Seagar, C. Doig, et al., 2007: Human and animal infections with Mycobacterium microti, Scotland. Emerging infectious diseases, 13, 1924-1927, doi:10.3201/eid1312.061536 (2007).

Falkinham, J. O., 3rd, 2015: Environmental sources of nontuberculous mycobacteria. Clin. Chest. Med., 36, 35-41, doi:10.1016/j.ccm.2014.10.003 (2015).

Falkinham, J. O., 3rd, M. D. Iseman, P. de Haas and D. van Soolingen, 2008: Mycobacterium avium in a shower linked to pulmonary disease. Journal of water and health,6, 209-213, doi:10.2166/wh.2008.032 (2008).

Frank, W., E. C. Reisinger, W. Brandt-Hamerla, et al., 2009: Mycobacterium microti-pulmonary tuberculosis in an immunocompetent patient. Wiener klinische Wochenschrift, 121, 282-286, doi:10.1007/s00508009-1164-0 (2009).

Garcia-Jimenez, W. L., J. M. Benitez-Medina, R. Martinez, et al., 2015: Non-tuberculous mycobacteria in wild boar (Sus scrofa) from Southern Spain: epidemiological, clinical and diagnostic concerns. Transboundary and emerging diseases, 62, 72-80, doi:10.1111/tbed.12083 (2015). 
Garcia-Jimenez, W. L., M. Cortes, J. M. Benitez-Medina, et al., 2016: Spoligotype diversity and 5-year trends of bovine tuberculosis in Extremadura, southern Spain. Tropical animal health and production, 48, 1533-1540, doi:10.1007/s11250-016-1124-4 (2016).

Gcebe, N. and T. M. Hlokwe, 2017: Non-tuberculous Mycobacteria in South African Wildlife: Neglected Pathogens and Potential Impediments for Bovine Tuberculosis Diagnosis.Frontiers in cellular and infection microbiology, 7, doi:Artn 15

10.3389/Fcimb.2017.00015 (2017).

Geiss, H. K., R. Feldhues, S. Niemann, et al., 2005: Landouzy septicemia (sepsis tuberculosa acutissima) due to Mycobacterium microti in an immunocompetent man. Infection, 33, 393-396, doi:10.1007/s15010005-5075-3 (2005).

Gethoffer, F., G. Sodeikat and K. Pohlmeyer, 2007: Reproductive parameters of wild boar (Sus scrofa) in three different parts of Germany. Eur J Wildlife Res,53, 287-297, doi:10.1007/s10344-007-0097-z (2007).

Ghielmetti, G., U. Friedel, S. Scherrer, et al., 2018: Non-tuberculous mycobacteria isolated from lymph nodes and faecal samples of healthy slaughtered cattle and the abattoir environment. Transboundary and emerging diseases, 65, 711-718, doi:10.1111/tbed.12793 (2018).

Ghielmetti, G., S. Scherrer, U. Friedel, et al., 2017: Epidemiological tracing of bovine tuberculosis in Switzerland, multilocus variable number of tandem repeat analysis of Mycobacterium bovis and Mycobacterium caprae . PloS one, 12, e0172474, doi:10.1371/journal.pone.0172474 (2017).

Gortazar, C., M. J. Torres, P. Acevedo, et al., 2011: Fine-tuning the space, time, and host distribution of mycobacteria in wildlife. BMC microbiology, 11, 27, doi:10.1186/1471-2180-11-27 (2011).

Gortazar, C., M. J. Torres, J. Vicente, et al., 2008: Bovine tuberculosis in Donana biosphere reserve: the role of wild ungulates as disease reservoirs in the last Iberian lynx strongholds. PloS one, 3, e2776, doi:10.1371/journal.pone.0002776 (2008).

Griffith, D. E., T. Aksamit, B. A. Brown-Elliott, et al., 2007: An official ATS/IDSA statement: diagnosis, treatment, and prevention of nontuberculous mycobacterial diseases.Am. J. Respir. Crit. Care Med., 175, 367-416, doi:10.1164/rccm.200604-571ST (2007).

Gupta, R. S., B. Lo and J. Son, 2018: Phylogenomics and comparative genomic studies robustly support division of the Genus Mycobacterium into an Emended GenusMycobacterium and four novel Genera. Frontiers in microbiology, 9, 67, doi:10.3389/fmicb.2018.00067 (2018).

Hilborn, E. D., M. A. Yakrus, T. C. Covert, et al., 2008: Molecular comparison of Mycobacterium aviumisolates from clinical and environmental sources. Applied and environmental microbiology, 74, 4966-4968, doi:10.1128/AEM.0290007 (2008).

Hoefsloot, W., J. van Ingen, C. Andrejak, et al., 2013: The geographic diversity of nontuberculous mycobacteria isolated from pulmonary samples: an NTM-NET collaborative study. The European respiratory journal, 42, 1604-1613, doi:10.1183/09031936.00149212 (2013).

Hoffmann, B., K. Depner, H. Schirrmeier and M. Beer, 2006: A universal heterologous internal control system for duplex real-time RT-PCR assays used in a detection system for pestiviruses. Journal of virological methods, 136, 200-209, doi:10.1016/j.jviromet.2006.05.020 (2006).

Johansen, M. D., J. L. Herrmann and L. Kremer, 2020: Non-tuberculous mycobacteria and the rise of Mycobacterium abscessus. Nature reviews. Microbiology, doi:10.1038/s41579-020-0331-1 (2020).

Johansen, T. B., I. Olsen, M. R. Jensen, et al., 2007: New probes used for IS1245 and IS1311 restriction fragment length polymorphism of Mycobacterium avium subsp.avium and Mycobacterium avium subsp. hominissuisisolates of human and animal origin in Norway. BMC microbiology,7, 14, doi:10.1186/1471-21807-14 (2007). 
Ko, R. E., S. M. Moon, S. Ahn, et al., 2018: Changing epidemiology of nontuberculous mycobacterial lung diseases in a tertiary referral hospital in Korea between 2001 and 2015. Journal of Korean medical science, 33, e65, doi:10.3346/jkms.2018.33.e65 (2018).

Kodana, M., N. Tarumoto, T. Kawamura, et al., 2016: Utility of the MALDI-TOF MS method to identify nontuberculous mycobacteria. Journal of infection and chemotherapy : official journal of the Japan Society of Chemotherapy, 22, 32-35, doi:10.1016/j.jiac.2015.09.006 (2016).

Kuznetcova, T. I., A. Sauty and C. P. Herbort, 2012: Uveitis with occult choroiditis due to Mycobacterium kansasii: limitations of interferon-gamma release assay (IGRA) tests (case report and mini-review on ocular non-tuberculous mycobacteria and IGRA cross-reactivity). International ophthalmology, 32, 499-506, doi:10.1007/s10792-012-9588-3 (2012).

Lara, G. H., M. G. Ribeiro, C. Q. Leite, et al., 2011: Occurrence of Mycobacterium spp. and other pathogens in lymph nodes of slaughtered swine and wild boars (Sus scrofa ). Research in veterinary science, 90, 185-188, doi:10.1016/j.rvsc.2010.06.009 (2011).

Latshang, T. D., C. M. Lo Cascio and E. W. Russi, 2011: [Nontuberculous mycobacterial infections of the lung]. Therapeutische Umschau. Revue therapeutique, 68, 402-406, doi:10.1024/0040-5930/a000184 (2011).

Leuenberger, R., 2004: Surveillance of wild boar in Switzerland: prevalence of infections relevant to domestic pigs. Inaugural Dissertation, (2004).

Lim, H. J., C. M. Park, Y. S. Park, et al., 2011: Isolation of multiple nontuberculous mycobacteria species in the same patients. International journal of infectious diseases : IJID : official publication of the International Society for Infectious Diseases, 15, e795-798, doi:10.1016/j.ijid.2011.07.004 (2011).

Lotz, A., A. Ferroni, J. L. Beretti, et al., 2010: Rapid identification of mycobacterial whole cells in solid and liquid culture media by matrix-assisted laser desorption ionization-time of flight mass spectrometry. $J$ Clin Microbiol,48, 4481-4486, doi:10.1128/JCM.01397-10 (2010).

Mann, E., M. Dzieciol, B. U. Metzler-Zebeli, et al., 2014: Microbiomes of unreactive and pathologically altered ileocecal lymph nodes of slaughter pigs.Applied and environmental microbiology, 80, 193-203, doi:10.1128/AEM.03089-13 (2014).

Maria, F., S. Corina, G. Monika, et al., 2015: Red deer as maintenance host for bovine tuberculosis, Alpine region. Emerging Infectious Disease journal, 21, doi:10.3201/eid2103.141119 (2015).

Martin-Hernando, M. P., U. Hofle, J. Vicente, et al., 2007: Lesions associated with Mycobacterium tuberculosis complex infection in the European wild boar.Tuberculosis, 87, 360-367, doi:10.1016/j.tube.2007.02.003 (2007).

Martinelli, N., E. Pavoni, D. Filogari, et al., 2015: Hepatitis E virus in wild boar in the central northern part of Italy. Transboundary and emerging diseases, 62, 217-222, doi:10.1111/tbed.12118 (2015).

Massei, G., J. Kindberg, A. Licoppe, et al., 2015: Wild boar populations up, numbers of hunters down? A review of trends and implications for Europe. Pest management science, 71, 492-500, doi:10.1002/ps.3965 (2015).

Mediavilla-Gradolph, M. C., I. De Toro-Peinado, M. P. Bermudez-Ruiz, et al., 2015: Use of MALDI-TOF MS for identification of nontuberculous Mycobacterium species isolated from clinical specimens. BioMed research international, 2015, 854078, doi:10.1155/2015/854078 (2015).

Michelet, L., K. de Cruz, G. Zanella, et al., 2015: Infection with Mycobacterium microti in animals in France. J Clin Microbiol, 53, 981-985, doi:10.1128/JCM.02713-14 (2015).

Mobius, P., P. Lentzsch, I. Moser, et al., 2006: Comparative macrorestriction and RFLP analysis of Mycobacterium avium subsp. avium and Mycobacterium avium subsp. hominissuis isolates from man, pig, and cattle. Vet. Microbiol., 117, 284-291, doi:10.1016/j.vetmic.2006.05.005 (2006). 
Murugaiyan, J., A. Lewin, E. Kamal, et al., 2018: MALDI spectra database for rapid discrimination and subtyping of Mycobacterium kansasii . Frontiers in microbiology, 9, 587, doi:10.3389/fmicb.2018.00587 (2018).

Muwonge, A., C. Kankya, T. B. Johansen, et al., 2012: Non-tuberculous mycobacteria isolated from slaughter pigs in Mubende district, Uganda. BMC veterinary research, 8, 52, doi:10.1186/1746-6148-8-52 (2012).

Naranjo, V., C. Gortazar, J. Vicente and J. de la Fuente, 2008: Evidence of the role of European wild boar as a reservoir of Mycobacterium tuberculosis complex. Veterinary microbiology, 127, 1-9, doi:10.1016/j.vetmic.2007.10.002 (2008).

Niemann, S., E. Richter, H. Dalugge-Tamm, et al., 2000: Two cases of Mycobacterium microtiderived tuberculosis in HIV-negative immunocompetent patients. Emerging infectious diseases, 6, 539-542, doi:10.3201/eid0605.000516 (2000).

Nigsch, A., W. Glawischnig, Z. Bago and N. Greber, 2018: Mycobacterium caprae infection of red deer in western Austria-optimized use of pathology data to infer infection dynamics. Frontiers in veterinary science, 5, 350, doi:10.3389/fvets.2018.00350 (2018).

Nishiuchi, Y., T. Iwamoto and F. Maruyama, 2017: Infection sources of a common non-tuberculous mycobacterial pathogen, Mycobacterium avium Complex.Frontiers in medicine, 4, 27, doi:10.3389/fmed.2017.00027 (2017).

Nugent, G., C. Gortazar and G. Knowles, 2015: The epidemiology of Mycobacterium bovis in wild deer and feral pigs and their roles in the establishment and spread of bovine tuberculosis in New Zealand wildlife. New Zealand veterinary journal, 63, 54-67, doi:10.1080/00480169.2014.963792 (2015).

Nukui, Y., H. Nakamura, H. Ishioka, et al., 2014: Synovitis of the wrist caused by Mycobacterium florentinum . Infection, 42, 437-440, doi:10.1007/s15010-013-0561-5 (2014).

Oliver, W. L. R., IUCN/SSC Pigs and Peccaries Specialist Group. and IUCN/SSC Hippo Specialist Group., 1993:Pigs, peccaries, and hippos : status survey and conservation action plan . IUCN, Gland, Switzerland.

Pate, M., U. Zajc, D. Kusar, et al., 2016: Mycobacterium spp. in wild game in Slovenia. Veterinary journal, 208, 93-95, doi:10.1016/j.tvjl.2015.10.004 (2016).

Pranada, A. B., 2015: Mycobacteria identification by MALDI Biotyper System: Evolution of database content and evaluation criteria. ECCMID 2015, Copenhagen, (2015).

Queiros, J., M. Villar, A. Hernandez-Jarguin, et al., 2019: A metaproteomics approach reveals changes in mandibular lymph node microbiota of wild boar naturally exposed to an increasing trend of Mycobacterium tuberculosiscomplex infection. Tuberculosis, 114, 103-112, doi:10.1016/j.tube.2018.12.003 (2019).

Ravva, S. V., L. A. Harden and C. Z. Sarreal, 2017: Characterization and differentiation of Mycobacterium avium subsp. paratuberculosis from other mycobacteria using matrix assisted laser desorption/ionization time-of-flight mass spectrometry. Frontiers in cellular and infection microbiology, 7, 297, doi:10.3389/fcimb.2017.00297 (2017).

Reed, J. L., Z. J. Walker, D. Basu, et al., 2016: Highly sensitive sequence specific qPCR detection of Mycobacterium tuberculosis complex in respiratory specimens.Tuberculosis, 101, 114-124, doi:10.1016/j.tube.2016.09.002 (2016).

Ricchi, M., A. Mazzarelli, A. Piscini, et al., 2017: Exploring MALDI-TOF MS approach for a rapid identification of Mycobacterium avium ssp.paratuberculosis field isolates. Journal of applied microbiology, 122, 568-577, doi:10.1111/jam.13357 (2017).

Richomme, C., M. L. Boschiroli, J. Hars, et al., 2010: Bovine tuberculosis in livestock and wild boar on the Mediterranean island, Corsica. Journal of wildlife diseases,46, 627-631, doi:10.7589/0090-3558-46.2.627 (2010). 
Richter, E., S. Niemann, F. O. Gloeckner, et al., 2002: Mycobacterium holsaticum sp. nov.International journal of systematic and evolutionary microbiology, 52, 1991-1996, doi:10.1099/00207713-52-6-1991 (2002).

Rodriguez-Campos, S., N. H. Smith, M. B. Boniotti and A. Aranaz, 2014: Overview and phylogeny of Mycobacterium tuberculosis complex organisms: Implications for diagnostics and legislation of bovine tuberculosis. Research in veterinary science, doi:10.1016/j.rvsc.2014.02.009 (2014).

Saleeb, P. G., S. K. Drake, P. R. Murray and A. M. Zelazny, 2011: Identification of mycobacteria in solidculture media by matrix-assisted laser desorption ionization-time of flight mass spectrometry. J Clin Microbiol, 49, 1790-1794, doi:10.1128/JCM.02135-10 (2011).

Santos, N., M. Correia-Neves, S. Ghebremichael, et al., 2009: Epidemiology of Mycobacterium bovisinfection in wild boar (Sus scrofa ) from Portugal. Journal of wildlife diseases, 45, 1048-1061, doi:10.7589/0090-355845.4.1048 (2009).

Sawai, T., Y. Inoue, S. Doi, et al., 2006: A case of Mycobacterium nonchromogenicum pulmonary infection showing multiple nodular shadows in an immunocompetent patient. Diagnostic microbiology and infectious disease, 54, 311-314, doi:10.1016/j.diagmicrobio.2005.11.005 (2006).

Scherrer, S., P. Landolt, N. Carroli and R. Stephan, 2018: Molecular Characterization of Mycobacterium avium subsp. hominissuis of two groups of lymph nodes, being intradermal tuberculin or interferon-gamma test positive and negative, isolated from Swiss cattle at slaughter. Frontiers in veterinary science, 5, 32, doi:10.3389/fvets.2018.00032 (2018).

Schinsky, M. F., M. M. McNeil, A. M. Whitney, et al., 2000: Mycobacterium septicum sp. nov., a new rapidly growing species associated with catheter-related bacteraemia.International journal of systematic and evolutionary microbiology, 50 Pt 2, 575-581, doi:10.1099/00207713-50-2-575 (2000).

Schoning, J. M., N. Cerny, S. Prohaska, et al., 2013: Surveillance of bovine tuberculosis and risk estimation of a future reservoir formation in wildlife in Switzerland and Liechtenstein. PloS one, 8, e54253, doi:10.1371/journal.pone.0054253 (2013).

Schulz, K., E. Olsevskis, C. Staubach, et al., 2019: Epidemiological evaluation of Latvian control measures for African swine fever in wild boar on the basis of surveillance data. Scientific reports, 9, 4189, doi:10.1038/s41598-019-40962-3 (2019).

Spitz, F., 1992: General-model of the spatial and social-organization of the wild boars (Sus-scrofaL.). Ongules / Ungulates 91 , 385-389 (1992).

Stepanyan, I. E., A. S. Zaytseva, T. R. Bagdasaryan, et al., 2019: Nontuberculous mycobacterial co-infection in HIV-negative patients with pulmonary tuberculosis. European Respiratory Journal, 54, doi:10.1183/13993003.congress2019.PA4644 (2019).

Syed, S. S., O. Aderinboye, K. E. Hanson and E. D. Spitzer, 2010: Acute cervical lymphadenitis caused by Mycobacterium florentinum . Emerging infectious diseases,16, 1486-1487, doi:10.3201/eid1609.100433 (2010).

Taillard, C., G. Greub, R. Weber, et al., 2003: Clinical implications of Mycobacterium kansasii species heterogeneity: Swiss National Survey. J. Clin. Microbiol., 41, 1240-1244 (2003).

Tanaka, S., Y. Hoshino, T. Sakagami, et al., 2019: Pathogenicity of Mycolicibacterium phlei, a nonpathogenic nontuberculous mycobacterium in an immunocompetent host carrying anti-interferon gamma autoantibodies: a case report. BMC infectious diseases, 19, 454, doi:10.1186/s12879-019-4050-z (2019).

Telenti, A., F. Marchesi, M. Balz, et al., 1993: Rapid identification of mycobacteria to the species level by polymerase chain reaction and restriction enzyme analysis. J. Clin. Microbiol., 31, 175-178 (1993).

Tortoli, E., 2006: The new mycobacteria: an update. FEMS immunology and medical microbiology, 48, 159-178, doi:10.1111/j.1574-695X.2006.00123.x (2006). 
Tortoli, E., 2014: Microbiological features and clinical relevance of new species of the genus Mycobacterium . Clinical microbiology reviews, 27, 727-752, doi:10.1128/CMR.00035-14 (2014).

Tortoli, E., L. Rindi, K. S. Goh, et al., 2005: Mycobacterium florentinum sp. nov., isolated from humans. International journal of systematic and evolutionary microbiology, 55, 1101-1106, doi:10.1099/ijs.0.63485-0 (2005).

Trcka, I., J. Lamka, R. Suchy, et al., 2006: Mycobacterial infections in European wild boar (Sus scrofa) in the Czech Republic during the years 2002 to 2005. Vet Med-Czech, 51, 320-332 (2006).

Turenne, C. Y., M. Semret, D. V. Cousins, et al., 2006: Sequencing of hsp65 distinguishes among subsets of the Mycobacterium avium complex. J. Clin. Microbiol., 44, 433-440, doi:10.1128/JCM.44.2.433-440.2006 (2006).

van Ingen, J., C. Y. Turenne, E. Tortoli, et al., 2018: A definition of the Mycobacterium aviumcomplex for taxonomical and clinical purposes, a review.International journal of systematic and evolutionary microbiology, 68, 3666-3677, doi:10.1099/ijsem.0.003026 (2018).

van Soolingen, D., A. G. van der Zanden, P. E. de Haas, et al., 1998: Diagnosis of Mycobacterium microti infections among humans by using novel genetic markers. J Clin Microbiol, 36, 1840-1845 (1998).

Vicente, J., U. Hofle, J. M. Garrido, et al., 2006: Wild boar and red deer display high prevalences of tuberculosis-like lesions in Spain. Veterinary research, 37, 107-119, doi:10.1051/vetres:2005044 (2006).

Walayat, S., T. Awwal, M. Roy and S. Ahmad, 2018: Mycobacterium neoaurum line-related bacteremia with pulmonary involvement: Case report and review of literature.IDCases, 11, 88-90, doi:10.1016/j.idcr.2018.01.004 (2018).

Wilson, J. W., A. C. Jagtiani and N. L. Wengenack, 2019: Mycobacterium scrofulaceum disease: experience from a tertiary medical centre and review of the literature.Infectious diseases, 51, 602-609, doi:10.1080/23744235.2019.1634281 (2019).

Yagi, K., K. Morimoto, M. Ishii, et al., 2018: Clinical characteristics of pulmonary Mycobacterium lentiflavum disease in adult patients. International journal of infectious diseases : IJID : official publication of the International Society for Infectious Diseases, 67, 65-69, doi:10.1016/j.ijid.2017.12.001 (2018).

Yilmaz, N., E. Y. Ucar and L. Saglam, 2017: Mycobacterium Tuberculosis and Nontuberculous Mycobacteria Coinfection of the Lungs. Turk Thorac J, 18, 23-26, doi:10.5152/TurkThoracJ.2017.16034 (2017).

Table 1. Identification of nontuberculous mycobacteria isolated from wild boars and human clinical relevance. A total of 111 nontuberculous mycobacteria isolates belonging to 24 known species and three potentially undescribed Mycobacterium species were cultured from 176 wild boar mandibular lymph nodes. Sequence analysis was used as gold standard method. Results of identifications based on MALDITOF MS applying two different log scores value cut offs are shown. Discrepant results intended as i) no species identification by MALDI-TOF analysis or ii) assignment of a discrepant species compared to sequence analysis are highlighted.

Species identified by

sequence analysis

(16S rRNA, rpoB

and $h s p 65)$

Identification by MALDI-TOF MS

Mycobacterium

avium

Mycobacterium

nonchro-

mogenicum

$\begin{array}{ll}\mathrm{LSV}>2 & \mathrm{LSV}>1.8\end{array}$

$24 \quad 25$

15

24

$\mathrm{LSV}>1.8$
Identification by Human clinical MALDI-TOF MS relevance ${ }^{+}$)

4

+ (van Ingen et al., 2018) + (Sawai et al., 2006) 


\begin{tabular}{|c|c|c|c|c|}
\hline $\begin{array}{l}\text { Species identified by } \\
\text { sequence analysis } \\
\text { (16S rRNA, rpoB } \\
\text { and } h s p 65)\end{array}$ & & $\begin{array}{l}\text { Identification by } \\
\text { MALDI-TOF MS }\end{array}$ & $\begin{array}{l}\text { Identification by } \\
\text { MALDI-TOF MS }\end{array}$ & $\begin{array}{l}\text { Human clinical } \\
\text { relevance }^{+)}\end{array}$ \\
\hline $\begin{array}{l}\text { Mycobacterium } \\
\text { vaccae }\end{array}$ & 8 & 8 & 8 & - \\
\hline $\begin{array}{l}\text { Mycobacterium } \\
\text { engbaekii }\end{array}$ & 6 & 3 & 6 & - \\
\hline $\begin{array}{l}\text { Mycobacterium } \\
\text { neoaurum }\end{array}$ & 6 & 4 & 6 & $\begin{array}{l}+ \text { (Walayat et al., } \\
2018)\end{array}$ \\
\hline $\begin{array}{l}\text { Mycobacterium } \\
\text { nebraskense }\end{array}$ & 4 & 1 & 4 & $+($ Tortoli, 2006$)$ \\
\hline $\begin{array}{l}\text { Mycobacterium } \\
\text { lentiflavum }\end{array}$ & 4 & 4 & 4 & $\begin{array}{l}+ \text { (Yagi et al., } \\
2018)\end{array}$ \\
\hline $\begin{array}{l}\text { Mycobacterium } \\
\text { colombiense }\end{array}$ & 3 & 0 & 0 & $+($ Tortoli, 2006) \\
\hline $\begin{array}{l}\text { Mycobacterium } \\
\text { diernhoferi }\end{array}$ & 3 & 3 & 3 & - \\
\hline $\begin{array}{l}\text { Mycobacterium } \\
\text { florentinum }\end{array}$ & 3 & 2 & 3 & $\begin{array}{l}+(\text { Tortoli et al., } \\
2005)\end{array}$ \\
\hline $\begin{array}{l}\text { Mycobacterium } \\
\text { peregrinum }\end{array}$ & 3 & 3 & 3 & $\begin{array}{l}+(\text { Hoefsloot et } \\
\text { al., 2013) }\end{array}$ \\
\hline $\begin{array}{l}\text { Mycobacterium } \\
\text { bourgelatii }\end{array}$ & 2 & 2 & 2 & - \\
\hline $\begin{array}{l}\text { Mycobacterium } \\
\text { celatum }\end{array}$ & 2 & 2 & 2 & $\begin{array}{l}+(\text { Chavarria et } \\
\text { al., 2018) }\end{array}$ \\
\hline $\begin{array}{l}\text { Mycobacterium } \\
\text { chimaera- } \\
\text { intracelullare } \\
\text { group }\end{array}$ & 2 & 2 & 2 & $\begin{array}{l}+(\text { van Ingen et } \\
\text { al., 2018) }\end{array}$ \\
\hline $\begin{array}{l}\text { Mycobacterium } \\
\text { intermedium }\end{array}$ & 2 & 2 & 2 & - \\
\hline $\begin{array}{l}\text { Mycobacterium } \\
\text { scrofulaceum }\end{array}$ & 2 & 0 & 0 & $\begin{array}{l}+ \text { (Wilson et al., } \\
2019)\end{array}$ \\
\hline $\begin{array}{l}\text { Mycobacterium } \\
\text { phlei }\end{array}$ & 2 & 1 & 2 & $\begin{array}{l}+ \text { (Tanaka et al., } \\
2019)\end{array}$ \\
\hline $\begin{array}{l}\text { Mycobacterium } \\
\text { fortuitum complex }\end{array}$ & 1 & 1 & 1 & $\begin{array}{l}+(\text { Hoefsloot et } \\
\text { al., 2013) }\end{array}$ \\
\hline $\begin{array}{l}\text { Mycobacterium } \\
\text { holsaticum }\end{array}$ & 1 & 1 & 1 & $\begin{array}{l}+ \text { (Richter et al., } \\
2002)\end{array}$ \\
\hline $\begin{array}{l}\text { Mycobacterium } \\
\text { interjectum }\end{array}$ & 1 & 1 & 1 & $\begin{array}{l}+(\text { Dholakia } \\
2017)\end{array}$ \\
\hline $\begin{array}{l}\text { Mycobacterium } \\
\text { monacense }\end{array}$ & 1 & 0 & 0 & $+($ Tortoli, 2014) \\
\hline $\begin{array}{l}\text { Mycobacterium } \\
\text { septicum }\end{array}$ & 1 & 1 & 1 & $\begin{array}{l}+(\text { Schinsky et } \\
\text { al., 2000) }\end{array}$ \\
\hline $\begin{array}{l}\text { Mycobacterium } \\
\text { terrae complex }\end{array}$ & 1 & 0 & 0 & / \\
\hline $\begin{array}{l}\text { Mycobacterium } \\
\text { vulneris }\end{array}$ & 1 & 0 & 0 & $+($ Tortoli, 2014) \\
\hline
\end{tabular}


Species identified by

sequence analysis

(16S rRNA, гроB

and hsp65)

Identification by Identification by Human clinical

Mycobacterium

MALDI-TOF MS

MALDI-TOF MS

relevance $^{+}$)

sp. (not

described)

Total

111

0

0

/

80

100

+) Human clinical relevance according to previously reported cased (opportunistic pathogen: +; unknown pathogenicity or saprophytes: -)

Table 2. Macroscopic and histological findings compatible with mycobacterial infection in lymph nodes of hunted wild boars positive forMycobacterium spp. are resumed.

\begin{tabular}{|c|c|c|c|c|c|}
\hline $\begin{array}{l}\text { Examination of } \\
\text { lymph nodes }\end{array}$ & $\begin{array}{l}\text { Examination of } \\
\text { lymph nodes }\end{array}$ & $\begin{array}{l}\text { Examination of } \\
\text { lymph nodes }\end{array}$ & $\begin{array}{l}\text { Examination of } \\
\text { lymph nodes }\end{array}$ & $\begin{array}{l}\text { Species of } \\
\text { mycobacteria } \\
\text { identified }\end{array}$ & $\begin{array}{l}\text { Species of } \\
\text { mycobacteria } \\
\text { identified }\end{array}$ \\
\hline$\overline{\mathrm{n}}$ & $\begin{array}{l}\text { Macroscopic } \\
\text { findings }+)\end{array}$ & $\begin{array}{l}\text { Histological } \\
\text { findings }++)\end{array}$ & $\begin{array}{l}\text { Histological } \\
\text { findings }++)\end{array}$ & & \\
\hline 10 & $\begin{array}{l}\text { Single or } \\
\text { multiple nodules }\end{array}$ & + & + & $\begin{array}{l}\text { M. microti }(4) \\
\text { Co-infection } M \text {. } \\
\text { microti and } M \text {. } \\
\text { neoaurum (1) } \\
\text { M. florentinum } \\
\text { (3) } \\
\text { M. avium subsp. } \\
\text { hominissuis (1) } \\
\text { M. nonchro- } \\
\text { mogenicum } \\
(1)\end{array}$ & $\begin{array}{l}\text { M. microti (4) } \\
\text { Co-infection } M \text {. } \\
\text { microti and } M \text {. } \\
\text { neoaurum (1) } \\
\text { M. florentinum } \\
\text { (3) } \\
\text { M. avium subsp. } \\
\text { hominissuis (1) } \\
\text { M. nonchro- } \\
\text { mogenicum } \\
(1)\end{array}$ \\
\hline 4 & $\begin{array}{l}\text { Single or } \\
\text { multiple nodules }\end{array}$ & - & - & $\begin{array}{l}\text { M. avium subsp. } \\
\text { hominissuis }(1) \\
\text { M. vulneris }(1) \\
\text { M. lentiflavum } \\
\text { (1) } \\
\text { M. neoaurum (1) }\end{array}$ & $\begin{array}{l}\text { M. avium subsp. } \\
\text { hominissuis (1) } \\
\text { M. vulneris (1) } \\
\text { M. lentiflavum } \\
\text { (1) } \\
\text { M. neoaurum (1) }\end{array}$ \\
\hline 12 & + & nd & nd & $\begin{array}{l}\text { M. avium subsp. } \\
\text { hominissuis }(9) \\
\text { M. nonchro- } \\
\text { mogenicum } \\
(3)\end{array}$ & $\begin{array}{l}\text { M. avium subsp. } \\
\text { hominissuis (9) } \\
\text { M. nonchro- } \\
\text { mogenicum } \\
\text { (3) }\end{array}$ \\
\hline 75 & - & nd & nd & $\begin{array}{l}\text { All species listed } \\
\text { in Tabl. } 1 \text { with } \\
\text { the exception of } \\
\text { M. microti and } \\
\text { M. florentinum }\end{array}$ & $\begin{array}{l}\text { All species listed } \\
\text { in Tabl. } 1 \text { with } \\
\text { the exception of } \\
\text { M. microti and } \\
\text { M. florentinum }\end{array}$ \\
\hline
\end{tabular}

+, macroscopic or histological finding present; - no macroscopic or histological findings; nd, not done. +) 
Macroscopic findings comprised in all cases enlargement, discoloration and induration. ++) Histological findings comprised focal-extensive necrosis (mild to moderate), granulomatous lymphadenitis (moderate) as well as reactive hyperplasia (moderate to severe) and eosinophilic lymphadenitis (mild to moderate).

Figure 1. Geographic distribution of mycobacterial species identified from wild boars during 2017 and 2018 in the Canton Ticino in Southern Switzerland (green highlighted in the country map of Switzerland in Panel A). A) Hunting location of the five animals infected with Mycobacterium microti (red stars) and B) distribution of isolated nontuberculous mycobacterial species. Circled numbers represent the number of infected animals in each district.

Figure 2. Distribution of the isolated nontuberculous mycobacteria among three different age groups (juvenile, yearling and adult) as found for wild boars investigated in 2017 and 2018. Adult wild boars were more prone to be infected with mycobacteria (74.4\%) in comparison to juvenile animals $(54.9 \%)$ or yearlings $(45.8 \%)$.

Figure 3. Histological findings from a mandibular lymph node presenting histological lesions compatible with tuberculosis and tested positive for Mycobacterium microti. (A) Overview of a granulomatous lymphadenitis showing focal-extensive necrotic cores and dystrophic calcifications (arrow heads). The necrotic cores are surrounded by a mixed population of inflammatory cells and by a wide capsule of connective tissue (arrows), hematoxylin and eosin (HE; 40X). (B) Scanty acid-fast rods are visible in the necrotic debris. Occasionally, S-shaped bacilli, which are commonly associated withMycobacterium microti were observed intra- and extracellularly, Ziehl-Neelsen stain (40X). (C) Granuloma characterized by focalextensive necrosis and mild inflammatory infiltration of epithelioid macrophages, neutrophils, multinucleated Langhans type giant cells (arrows) and eosinophils is shown (HE; 40X).
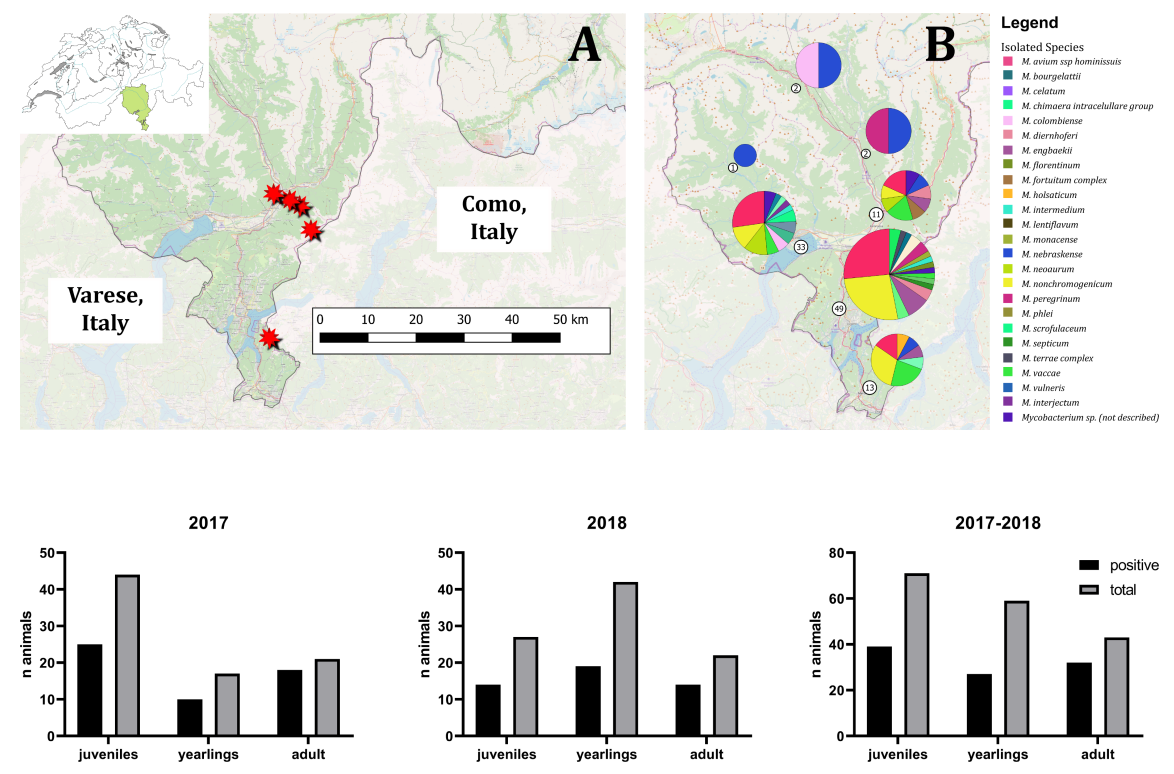


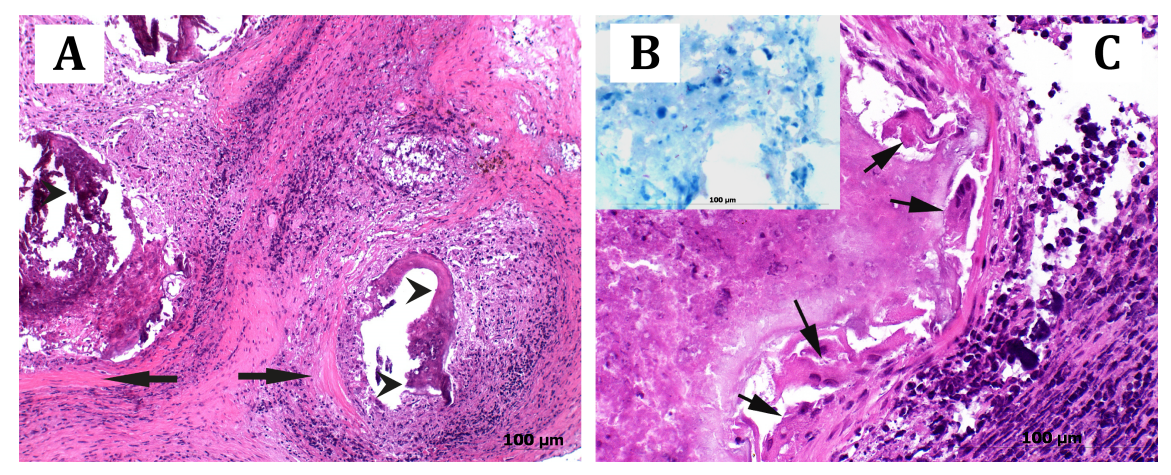

